\title{
Sleep Problems as Predictors in Attention-Deficit Hyperactivity Disorder: Causal Mechanisms, Consequences and Treatment
}

\author{
Yoo Hyun Um, Seung-Chul Hong, Jong-Hyun Jeong \\ Department of Psychiatry, St. Vincent's Hospital, College of Medicine, The Catholic University of Korea, Seoul, Korea
}

\begin{abstract}
Attention-deficit hyperactivity disorder (ADHD) is notorious for its debilitating consequences and early age of onset. The need for early diagnosis and intervention has frequently been underscored. Previous studies have attempted to clarify the bidirectional relationship between $A D H D$ and sleep problems, proposing a potential role for sleep problems as early predictors of $A D H D$. Sleep deprivation, sleep-disordered breathing, and circadian rhythm disturbances have been extensively studied, yielding evidence with regard to their induction of ADHD-like symptoms. Genetic-phenotypic differences across individuals regarding the aforementioned sleep problems have been elucidated along with the possible use of these characteristics for early prediction of $\mathrm{ADHD}$. The long-term consequences of sleep problems in individuals with ADHD include obesity, poor academic performance, and disrupted parent-child interactions. Early intervention has been proposed as an approach to preventing these debilitating outcomes of $\mathrm{ADHD}$, with novel treatment approaches ranging from melatonin and light therapy to myofunctional therapy and adjustments of the time point at which school starts.
\end{abstract}

KEY WORDS: Attention-deficit hyperactivity disorder; Sleep; Predictors; Treatment.

\section{INTRODUCTION}

Attention-deficit hyperactivity disorder (ADHD) is one of the most common psychiatric disorders in children with prevalence rates of up to $10 \%$ among those aged 6 to 17 years old. ${ }^{1-3)}$ The core symptoms of ADHD are comprised of inattention, hyperactivity and impulsivity. However, the full spectrum of ADHD symptoms ranges from disruptive behaviors to emotional dysregulation, all of which can result in dire psychological, educational and psychiatric consequences. Previous studies have attempted to understand the disease in terms of either psychological models pertaining to cognitive processes ${ }^{4}$ or biopsychosocial considerations that address potential biological, environmental risk factors. ${ }^{2)}$ Given the early age of onset of ADHD patients, and the fact that its symptoms exert a major influence on patients' lives during adolescence and adulthood, recent studies have focused on the need to identify endophenotypes and risk factors that can assist in

\footnotetext{
Received: August 11, 2016 / Revised: September 6, 2016

Accepted: September 11, 2016

Address for correspondence: Jong-Hyun Jeong, MD, PhD Department of Psychiatry, College of Medicine, The Catholic University of Korea, 93 Jungbu-daero, Paldal-gu, Suwon 16247, Korea Tel: +82-31-249-7150, Fax: +82-31-248-6758 E-mail: anton3@catholic.ac.kr
}

the early detection and prevention of ADHD. ${ }^{5,6)}$ One of the most extensively researched areas in this domain concerns the sleep problems associated with ADHD. Complexities of the relationship between ADHD and sleep have been well delineated in the previous literatures, and numerous excellent reviews have been published, including papers elucidating sleep disorders in ADHD, pharmacological strategies, potential underlying neurobiological mechanisms of ADHD and sleep. ${ }^{7-9)}$ However, much more evidence is needed to validate propositions that sleep problems may be a potential causative factor of ADHD. Moreover, relatively few review papers have been published on the functional consequences of sleep problems in patients with ADHD, despite the clinical importance. Finally, there is relative paucity of data on treatment modalities other than conventional psychotropics for patients with concurrent ADHD and sleep problems.

The present article reviews studies supporting the role of sleep problems, especially sleep deprivation, sleep-disordered breathing (SDB), and circadian rhythm disturbance, as causative factors of ADHD. Additionally, previous reports regarding the consequences of sleep problems in ADHD as well as several recent studies on novel treatment approaches are discussed.

(a) This is an Open-Access article distributed under the terms of the Creative Commons Attribution Non-Commercial License (http://creativecommons.org/licenses/by-nc/4.0) which permits unrestricted non-commercial use, distribution, and reproduction in any medium, provided the original work is properly cited. 


\section{SLEEP PROBLEMS AS PREDICTORS OF ADHD}

Numerous previous studies have demonstrated the effects of sleep problems on inattention, hyperactivity and impulsivity, which are core symptoms of ADHD. ${ }^{10-12)}$ Indeed, the aforementioned studies have implicated sleep problems as potential causative factors of ADHD. Extant research has focused primarily on the impact of three sleep problems on ADHD symptoms, examining their potential role as predictive factors: sleep deprivation, SDB, and circadian rhythm disturbances.

\section{Sleep Deprivation}

At the cellular level, sleep deprivation impairs synaptic plasticity ${ }^{13)}$ increases hippocampal oxidative stress ${ }^{14)}$ and facilitates neuronal loss, ${ }^{15)}$ all of which can detrimentally affect neurocognitive function. Five-choice performance tests conducted with both humans and mice have found that sleep deprivation results in an especially marked impairment in the attentional domain. ${ }^{16)}$ Altered patterns of sustained attention were noted in auditory and visual performance tasks in sleep-deprived subjects ${ }^{17)}$ and deficits in vigilant attention due to sleep deprivation induced errors of commission. ${ }^{18)}$ Furthermore, sleep deprivation led to slowed responses to neurocognitive tasks, ${ }^{19)}$ suggesting possible delays in the appropriate allocation of attentional resources. Such attentional difficulties were presumed to stem from impairment in the top-down executive control of the brain, ${ }^{20)}$ and evidence has demonstrated disruption of default mode network of the brain ${ }^{21,22)}$ and changes in topographic electroencephalogram ${ }^{23)}$ during this process. Even one hour of sleep restriction resulted in significant event-related potential changes in children across attentional tasks. $^{24)}$

In terms of studies regarding behavioral problems, one extensive meta-analysis of the relationship between sleep deprivation and cognition in school-aged children found a significant increase in behavioral problems in children with shorter sleep duration. ${ }^{25)}$ Additionally, sleep deprivation resulted in a significant increment in alertness and emotional reactivity in children, which led to delinquency, long-term emotional and behavioral difficulties. ${ }^{26-28)}$ Consistent with such findings, sleep deprived subjects were more alert to negative stimuli, ${ }^{29)}$ and more susceptible to exaggerated aggressive impulses. ${ }^{30)}$ Emotional lability and impulsivity were all strongly correlated with sleep deprivation, ${ }^{31)}$ with the severity of emotional dysregulation worsening as a function of the degree of sleep restriction. $^{32)}$
Along with the aforementioned results on the deleterious effects of sleep deprivation and their induction of ADHD-like symptoms, previous research has demonstrated the possibility of a genetic or phenotypic disparity in vulnerability to the effects of sleep deprivation. ${ }^{33,34)}$ More research is needed to examine the suggestion that sleep-deprived children may have an intrinsic susceptibility to ADHD and that sleep deprivation may serve as a potential predictor of ADHD.

\section{Sleep-disordered Breathing}

SDB induces an intermittent hypoxemic state during the night and patients with this condition suffer from sleep fragmentation. ${ }^{35,36)}$ Hypoxemia and sleep fragmentation reportedly induce systemic inflammation and oxidative damage that lead to endothelial dysfunction, which later can later result in vascular morbidity. ${ }^{36)}$ This inflammatory process subsequently leads to disruption of the blood brain barrier through alterations in microvessel permeability, which is one likely mechanism of the cognitive impairment associated with obstructive sleep apnea (OSA). Children with SDB were more vulnerable to oxidative stress than were those without SDB, and such susceptibility may help elucidate the mechanisms underlying the cognitive and attentional deficits in children with SDB. ${ }^{37,38)}$ In line with the aforementioned findings, hypoxemia has been found to contribute more than sleepiness to the poor continuous performance test results among patients with OSA. $^{39)}$ Detrimental effects of hypoxemia evoked by SDB on attention/vigilance have also been implicated in a meta-review. $^{40)}$

SDB has been demonstrated to be highly associated with symptoms of inattention and hyperactivity in previous studies $^{41-44)}$ and evidences of amelioration of behavioral, psychological problems after treatment interventions like adenotonsillectomy have been frequently reported, ${ }^{45)}$ suggesting a close link between SDB and ADHD symptoms. Pediatric patients with OSA reported lower scores on a divided attention steering simulation test, ${ }^{46)}$ and an event-related potential study revealed compensatory activation of central and temporal areas to make up for the reduced cognitive reserve in OSA children. ${ }^{47)}$ OSA had a major impact in all P300 measures, and possible disruptions in sustained attention and learning capacity have also been delineated. ${ }^{48)}$ Recent functional magnetic resonance imaging studies have revealed aberrant cerebral perfusion ${ }^{49)}$ reduced gray matter, ${ }^{50)}$ and altered patterns of intrinsic regional brain activity in patients with OSA, ${ }^{51)}$ which all might contribute to the attention, behavioral 
problems children with OSA.

Possible genetic-phenotypic interactions have been purported to be responsible for the pathogenesis of SDB, and several candidate genes like tumor necrosis factor-alpha, C-reactive protein, interleukin-6 (IL-6) genes, with their major impact on inflammatory process, have been researched. ${ }^{52-54)}$ Individuals with the aforementioned genetic susceptibility might be more likely to be afflicted with not only the SDB disease process but also with ADHD-like symptoms in the long run.

\section{Circadian Rhythm Disturbances}

Circadian rhythm is pivotal for the maintenance of human cognition, behavior, and emotion ${ }^{55)}$ Circadian rhythm disruptions and their association with neuropsychiatric disorders have been demonstrated in the extant literatures. ${ }^{56}$ ) The frequent manifestation of circadian rhythm disturbances in patients with ADHD has led to attempts to explicate a link between ADHD symptoms and circadian rhythm.

Several studies have hypothesized that various underlying mechanisms are involved in the interaction between circadian rhythm and attention. Circadian rhythm may influence human attention through the modulation of tonic alertness ${ }^{57)}$ while one study elucidated the more pervasive role of circadian rhythm on cognition, advocating the possibility of the widespread distribution of local pacemakers in the brain. ${ }^{58)}$ Circadian rhythm affects not only one's ability to inhibit response to stimuli, ${ }^{59,60)}$ but also one's performance on tasks involving sustained attention. ${ }^{61)}$

Deleterious effects of circadian rhythm disturbances on social behaviors in children have been reported ${ }^{62)}$ along with effects of endogenous melatonin levels on behavioral problems in preschool-aged children. ${ }^{63)}$ Adolescents with eveningness chronotype were more subject to behavioral problems ${ }^{64)}$ and of the ADHD symptoms, inattention was significantly associated with eveningness chronotype in patients with ADHD, advocating the eveningness chronotype as a possible endophenotype of ADHD. ${ }^{65)}$

Several approaches to the early detection of circadian rhythm disturbances may be feasible. Salivary melatonin level differences between ADHD children and normal controls have been suggested ${ }^{66)}$ and possibility of early diagnosis of ADHD by measuring salivary dim light onset melatonin has also been studied. ${ }^{67}$ Moreover, genetic variability of circadian rhythm across individuals have been well documented in previous reports ${ }^{68)}$ and morningness-eveningness preferences have been explained at a genetic level in one study. ${ }^{69)}$ Possible epigenetic mecha- nisms with the modulation of sirtuin 1 gene involved in human circadian rhythm have also been reported. ${ }^{70)}$ Given its possible relationship to the subsequent development of ADHD symptoms, the elucidation of genetic susceptibility to circadian rhythm disturbances may assist clinicians in the early detection of circadian rhythm problems and the prevention of ADHD symptoms.

\section{CONSEQUENCES OF SLEEP PROBLEMS IN ADHD PATIENTS}

Considering a large portion of ADHD patients are in their childhood and adolescence, problems regarding school performances, obesity, psychiatric comorbidities, and parent-children interactions warrant more clinical attention. The aforementioned issues are frequently reported consequences of sleep problems in such patients, and they significantly affect the long-term prognosis of individuals with this order.

\section{Obesity}

Negative impacts of sleep deprivation, circadian rhythm disturbances, and SDB have been studied, with possible mechanisms linking the aforementioned sleep disturbances and obesity. Abundant studies repetitively reported that short sleep duration in children and adolescents is significantly associated with obesity. ${ }^{71-75)}$ Additionally, high incidence of hypercholesterolemia, insulin resistance, insulin sensitivity, higher glucose levels, and hypertension was reported in this population, increasing the risk of diabetes mellitus, metabolic syndrome, and cardiovascular problems in the future. ${ }^{76-80)}$ Potential underlying mechanism of short sleep duration inducing obesity is partially explained by increased ghrelin and cortisol levels in sleep deprived subjects. ${ }^{81-84)}$ Sleep loss inevitably affects physiological control of human body and with the interaction of the aforementioned hormonal changes, increasing appetite and reducing energy expenditure, ultimately resulting in obesity. ${ }^{85,86}$

The close relationship between SDB and obesity has been reiterated, and obesity has been identified as a major risk factor of SDB ${ }^{87)}$ Mechanisms involved in SDB causing obesity are controversial. Diversity of intestinal flora was disrupted due to intermittent hypoxia in mouse models of sleep apnea ${ }^{88)}$ and an increase in lipid synthesis, subsequent hyperlipidemia were noted in both lean and obese mice which were exposed to intermittent hypoxia. ${ }^{89,90)}$ Intermittent hypoxia also increases glucose metabolism and inflammatory reactions, ${ }^{91)}$ which can contribute to the 
development of obesity.

The crucial role of circadian rhythm in hormonal regulation is well established. Carbohydrate and lipid metabolism are all under regulatory control of circadian rhythm. ${ }^{92)}$ Circadian rhythm disturbances can cause disruptions in the regulatory control of clock genes on adipocytes, detrimentally affecting adipocyte metabolism, thereby inducing obesity. ${ }^{93)}$ Moreover, peripheral clocks in liver and intestine are also affected, and dyssynchrony between central and peripheral clocks results in alterations in homeostasis and metabolism. ${ }^{94)}$

\section{Poor Academic Performance}

The negative impact of sleep problems on academic performance of children and adolescents can have additive effect on patients with ADHD, who already have difficulty in schools due to ADHD symptoms. A meta-analytic review comprehensively delineated that poor sleep quality, short sleep duration, excessive sleepiness were correlated with poor academic performance.95) One Swedish study reported that students with short sleep duration were more liable to academic failure. ${ }^{96)}$ Late bedtimes, but not total sleep duration was associated with school failure in another study. ${ }^{97)}$ Norwegian adolescents with short sleep duration showed poorer academic achievements and more frequent habits that have detrimentally influence on health. ${ }^{98)}$ To back up further, Finnish, Chinese and Korean studies all concordantly demonstrated positive association between sleep difficulties and poor academic performances. ${ }^{99-101)}$

Deleterious effects of SDB on academic performance in children have been demonstrated in numerous previous studies. ${ }^{102-106)}$ Problems in school tasks likely stem from attention deficits and decreased learning capacity frequently shown in children with SDB, as reviewed earlier in this article. As in children with SDB, improvements in obstructive apnea-hypopnea index resulted in increase of academic measures. ${ }^{107)}$ Regardless of the disease severity, SDB was significantly associated with low academic achievements. ${ }^{108)}$ As with other possible correlates of $\mathrm{SDB}$, one study suggested low socioeconomic status as an independent predictor of poor academic performance in children with SDB. ${ }^{109)}$

Meanwhile, the dependence of academic performance on individual variability with regard to chronotype has been repeatedly reported. One meta-analysis revealed a negative correlation between the eveningness chronotype and academic achievements. ${ }^{110)}$ Morningness chronotypes were associated with higher levels of attention and better school grades. ${ }^{111)}$ Significant differences in cognitive tasks such as visual search tasks were revealed between morningness and eveningness chronotypes, and diurnal variations in brain activation to sustain alertness were suggested. ${ }^{112)}$

\section{Disrupted Parent-Child Interactions}

Despite the indispensable role of parents with children affected by ADHD and sleep problems, few reviews have demonstrated the impact of such sleep problems on parent-child interactions. General indices regarding mental health of mothers have been associated with their children's sleep, and less well-organized sleep patterns have been noted in children from poorly functioning families. ${ }^{113)}$ Mothers of children with sleep disturbances exhibited much higher psychological stress than did controls, obtaining increased scores on all factors of the General Health Questionnaire (GHQ). ${ }^{114)}$ Children's sleep quality significantly predicted that of their mothers, with maternal sleep quality associated with stress and fatigue. ${ }^{115)}$ Moreover, infants of mothers with low levels of depression and anxiety were more likely to recover from sleep problems than those with high levels of depression and anxiety after controlling for the influence of attachment patterns. ${ }^{116)}$ Sleep disturbances in early childhood were positively related to negative maternal perceptions of their child, ${ }^{117)}$ potentially interfering with the development of beneficial parent-child interactions. Disciplinary styles were also influential, with permissive, inconsistent parenting behaviors significantly correlated with sleep disturbances in children. ${ }^{118)}$

Sleep problems in ADHD patients should not be confined to the problems of patients themselves, but should be considered in a broader context involving the parents of the child. ${ }^{119)}$ Thus, comprehensive reviews of the parents' psychiatric history, parenting styles, attachment patterns and stress levels of parents are required.

\section{FUTURE TREATMENT CONSIDERATIONS FOR SLEEP PROBLEMS IN ADHD}

In addition to the pharmacological and behavioral interventions suggested by previous reviews, many promising treatment approaches have been tested for the future treatments in ADHD patients with sleep problems.

\section{Melatonin \\ Melatonin is well known for its central regulatory role in circadian rhythm and its concordant effect on energy}


expenditure and metabolism. ${ }^{120)}$ For this reason, efficacy of melatonin on sleep-wake cycle disturbances has been delineated. Also, recent research has revealed the antioxidant profiles of melatonin ${ }^{121)}$ and its atheroprotective effects. $^{122)}$ In animal models, reduction of cognitive impairment in sleep-deprived rats has been demonstrated, advocating protective effect of melatonin from oxidative stress. ${ }^{123)}$ Sleep-promoting effects of melatonin has been demonstrated in zebrafish models, ${ }^{124)}$ along with anxiolytic effects evident in both human and animal models. ${ }^{125)}$

Melatonin significantly improves sleep onset insomnia in ADHD patients, but there have been no conclusive evidences to support association between problematic behaviors and cognition. ${ }^{126)}$ Melatonin is generally well tolerated by pediatric patients with concurrent ADHD and chronic sleep onset insomnia, ${ }^{127)}$ and one long-term follow up study with mean follow up period of 3.7 years conducted in ADHD children with chronic sleep onset insomnia revealed the efficacy of melatonin without notable adverse effects. ${ }^{128)}$ Relatively few large scale studies have been conducted to evaluate optimal dosage, safety and long term effects of melatonin. More research is needed to confirm the scientific evidence in the routine prescription of melatonin in clinical settings.

\section{Light Therapy}

The pivotal role of light in the regulation of circadian rhythm has been well-established, with mealonopsincontaining retinal ganglion cells and suprachiasmatic nucleus involved in the process. ${ }^{129)}$ One epidemiological study in the United States reported a lower prevalence of ADHD in geographic regions with high solar intensity, suggesting that improvement in circadian rhythm disturbances are attributed to exposure to sunlight. ${ }^{130}$ Few studies have been conducted to test the efficacy of the bright light treatment in ADHD patients with sleep problems. One open trial in adult ADHD patients reported the amelioration of core symptoms of ADHD as well as mood symptoms after the implementation of morning light therapy in the ADHD symptoms with eveningness chronotype. ${ }^{131)}$ Adolescents with ADHD underwent 4 weeks of light therapy, and the study suggested potential effectiveness of light therapy as add-on therapy, with salivary melatonin levels as indicators of improvement. ${ }^{132)}$ However, the aforementioned studies did not include results regarding the therapeutic effect of light therapy on the 'sleep problems' in ADHD patients. More large-scale structured studies are needed to test the clinical effectiveness of light therapy in ameliorating sleep problems in
ADHD patients.

Accumulated evidence supports the frequent manifestation of the evennineness chronotype in patients with ADHD, suggesting the possibility of circadian rhythm disturbances as underlying mechanisms, underscoring the need for more research on the optimal schedule for light therapy and its efficacy in the treatment of ADHD patients with sleep problems.

\section{Myofunctional Therapy}

Mounting evidence indicates the improvement of polysomnography results after adenotonsillectomy, and early surgical intervention of mild SDB in ADHD children has been suggested to stop unnecessary long-term usage of methylphenidate. ${ }^{133)}$ However, with evidences supporting the recurrence of OSA after adenotonsillectomy due to orofacial growth, the importance of myofunctional therapy in pediatric patients with OSA has been comprehensively delineated in one study. ${ }^{134)}$ Myofunctional therapy is an exercise involving the muscles of face and mouth, ultimately promoting nasal-breathing in children. ${ }^{135)}$ Not only is myofunctional reeducation an effective post-operative intervention, ${ }^{136)}$ but its potential as a treatment for OSA in children has also been suggested by evidences that the pathogenesis of OSA involves disruptions in orofacial growth of children. ${ }^{137)}$ Detailed assessments of orofacial anatomical structures using systemized protocols are needed, and myofunctional therapy is a convenient yet efficient intervention to treat OSA and prevent recurrence of OSA in post-surgical pediatric patients. Still, due to the limited accumulation of evidences in applying myofunctional therapy in clinical settings, more research is needed to confirm the effectiveness of myofunctional therapy in pediatric populations.

\section{Neurofeedback}

Underarousal and deficient involvement of necessary cortical networks during performance tasks have been implicated as a theoretical background of ADHD in neuroimaging and electroencephalographic studies. ${ }^{138)}$ Neurofeedback is based on classical/operant conditioning involving sensory motor rhythm (SMR) training, which helps the brain to regulate its functioning. ${ }^{138)}$ Many previous literatures have reported the efficacy of neurofeedback in ameliorating core symptoms of ADHD, ${ }^{139)}$ but studies regarding associations between sleep problems in patients with ADHD and neurofeedback are relatively scarce.

The number of sleep spindles is frequently reduced in sleep deprived subjects, and seonsorimotor rhythm train- 
ing significantly increases the number of sleep spindles and total sleep time, indicating its possible efficacy for patients with insomnia. ${ }^{140,141)}$ The treatment effect of neurofeedback through vigilance stabilization which is often disrupted by circadian phase delay in ADHD patients was outlined in one review, ${ }^{142)}$ which underscored the need for more extensive research on neurofeedback.

\section{Adjustment of School Start Times}

Many literatures to date have demonstrated the beneficial effects of delaying school start times. Indeed, several stunning results have been published, reporting that even 25 minutes of school start time delay was associated with significant improvements in sleep duration, ${ }^{143)}$ and $50 \mathrm{mi}-$ nutes of delay with increased academic achievements. ${ }^{144)}$ One hour of delay in school start time was significantly associated with enhancement of attention as well as improvements in cognitive performances in students. ${ }^{145)}$ Students attending morning classes suffered more from sleep restriction than did those attending afternoon classes, ${ }^{146)}$ and a Brazilian study demonstrated the influence of school start time on the sleeping habits of students. ${ }^{147)}$ Moreover, in another study, delaying the school start time not only improved the quality of sleep, but also ameliorated mood and behavioral symptoms in adolescents. ${ }^{148)}$

The American Academy of Pediatrics recently published a policy statement strongly recommending delaying school start times to ameliorate chronic sleep deprivation among students and consequent diversity of problems including obesity and depression. ${ }^{149)} \mathrm{A}$ recent recommendation by the National Sleep Foundation suggests that the optimal sleep duration for school-aged children is 7 to 12 hours and that for adolescents is 7 to 11 hours. ${ }^{150}$ Considering all the deleterious consequences of insufficient sleep in children and adolescents as mentioned earlier in this article, implementing policies advocating delay of the school start times warrants special attention, and clinicians should recognize the potential impact of school start time on their patients' sleep patterns and circadian rhythm disturbances.

\section{CONCLUSION}

Intricacies of the relationship between ADHD and sleep remain elusive. However, many promising reports regarding the 'sleep phenotypes' of ADHD such as sleep deprivation, SDB and circadian rhythms disturbances suggest the possibility of identifying predictors of ADHD.
Knowledge of such predictors would allow the early detection and treatment of disorder. Clinicians should be aware of the potential impact of sleep problems on pediatric and adolescent patients with ADHD, including obesity, poor academic performance and disrupted parent-child interactions, since they may debilitate the patients and influence the long term prognosis of the patients. Novel treatment interventions could be used for ADHD patients with sleep problems, including melatonin, light therapy, neurofeedback, myofunctional therapy and adjustments of school start times to alleviate the aforementioned long-term debilitating consequences.

\section{REFERENCES}

1. Feldman HM, Reiff MI. Clinical practice. Attention deficit-hyperactivity disorder in children and adolescents. $N$ Engl J Med 2014;370:838-846.

2. Spencer TJ, Biederman J, Wilens TE, Faraone SV. Overview and neurobiology of attention-deficit/hyperactivity disorder. $J$ Clin Psychiatry 2002;63 Suppl 12:3-9.

3. Sung V, Hiscock H, Sciberras E, Efron D. Sleep problems in children with attention-deficit/hyperactivity disorder: prevalence and the effect on the child and family. Arch Pediatr Adolesc Med 2008;162:336-342.

4. Sergeant JA, Geurts H, Huijbregts S, Scheres A, Oosterlaan J. The top and the bottom of ADHD: a neuropsychological perspective. Neurosci Biobehav Rev 2003;27:583-592.

5. Gurevitz M, Geva R, Varon M, Leitner Y. Early markers in infants and toddlers for development of ADHD. J Atten Disord 2014;18:14-22.

6. Castellanos FX, Tannock R. Neuroscience of attention-deficit/ hyperactivity disorder: the search for endophenotypes. Nat Rev Neurosci 2002;3:617-628.

7. Stein MA, Weiss M, Hlavaty L. ADHD treatments, sleep, and sleep problems: complex associations. Neurotherapeutics 2012;9:509-517.

8. Owens J, Gruber R, Brown T, Corkum P, Cortese S, $\mathrm{O}$ 'Brien $\mathrm{L}$, et al. Future research directions in sleep and ADHD: report of a consensus working group. J Atten Disord 2013;17:550-564.

9. Konofal E, Lecendreux M, Cortese S. Sleep and ADHD. Sleep Med 2010;11:652-658.

10. Beebe DW. Cognitive, behavioral, and functional consequences of inadequate sleep in children and adolescents. Pediatr Clin North Am 2011;58:649-665.

11. Paavonen EJ, Räikkönen K, Lahti J, Komsi N, Heinonen $\mathrm{K}$, Pesonen AK, et al. Short sleep duration and behavioral symptoms of attention-deficit/hyperactivity disorder in healthy 7- to 8-year-old children. Pediatrics 2009;123: e857-e864.

12. Cassoff J, Wiebe ST, Gruber R. Sleep patterns and the risk for ADHD: a review. Nat Sci Sleep 2012;4:73-80.

13. Alhaider IA, Aleisa AM, Tran TT, Alzoubi KH, Alkadhi KA. Chronic caffeine treatment prevents sleep deprivation-induced impairment of cognitive function and synaptic plasticity. Sleep 2010;33:437-444.

14. Silva RH, Abílio VC, Takatsu AL, Kameda SR, Grassl C, Chehin $\mathrm{AB}$, et al. Role of hippocampal oxidative stress in 
memory deficits induced by sleep deprivation in mice. Neuropharmacology 2004;46:895-903.

15. Jan JE, Reiter RJ, Bax MC, Ribary U, Freeman RD, Wasdell MB. Long-term sleep disturbances in children: a cause of neuronal loss. Eur J Paediatr Neurol 2010;14: 380-390.

16. van Enkhuizen J, Acheson D, Risbrough V, Drummond S, Geyer MA, Young JW. Sleep deprivation impairs performance in the 5-choice continuous performance test: similarities between humans and mice. Behav Brain Res 2014;261:40-48.

17. Jung CM, Ronda JM, Czeisler CA, Wright KP Jr. Comparison of sustained attention assessed by auditory and visual psychomotor vigilance tasks prior to and during sleep deprivation. J Sleep Res 2011;20:348-355.

18. Lim J, Dinges DF. Sleep deprivation and vigilant attention. Ann N Y Acad Sci 2008;1129:305-322.

19. de Freitas Araújo D, de Almondes KM. Sleep and cognitive performance in children and pre-adolescents: a review. Biol Rhythm Res 2014;45:193-207.

20. Jackson ML, Gunzelmann G, Whitney P, Hinson JM, Belenky G, Rabat A, et al. Deconstructing and reconstructing cognitive performance in sleep deprivation. Sleep Med Rev 2013;17:215-225.

21. Wang Y, Liu H, Hitchman G, Lei X. Module number of default mode network: inter-subject variability and effects of sleep deprivation. Brain Res 2015;1596:69-78.

22. De Havas JA, Parimal S, Soon CS, Chee MW. Sleep deprivation reduces default mode network connectivity and anti-correlation during rest and task performance. Neuroimage 2012;59:1745-1751.

23. Gorgoni M, Ferlazzo F, Ferrara M, Moroni F, D'Atri A, Fanelli S, et al. Topographic electroencephalogram changes associated with psychomotor vigilance task performance after sleep deprivation. Sleep Med 2014;15:1132-1139.

24. Molfese DL, Ivanenko A, Key AF, Roman A, Molfese VJ, O'Brien LM, et al. A one-hour sleep restriction impacts brain processing in young children across tasks: evidence from event-related potentials. Dev Neuropsychol 2013;38: 317-336.

25. Astill RG, Van der Heijden KB, Van Ijzendoorn MH, Van Someren EJ. Sleep, cognition, and behavioral problems in school-age children: a century of research meta-analyzed. Psychol Bull 2012;138:1109-1138.

26. Gregory AM, Sadeh A. Sleep, emotional and behavioral difficulties in children and adolescents. Sleep Med Rev 2012;16:129-136.

27. Meldrum RC, Barnes JC, Hay C. Sleep deprivation, low self-control, and delinquency: a test of the strength model of self-control. J Youth Adolesc 2015;44:465-477.

28. Rosales-Lagarde A, Armony JL, Del Río-Portilla Y, TrejoMartínez D, Conde R, Corsi-Cabrera M. Enhanced emotional reactivity after selective REM sleep deprivation in humans: an fMRI study. Front Behav Neurosci 2012;6:25.

29. Anderson C, Platten CR. Sleep deprivation lowers inhibition and enhances impulsivity to negative stimuli. Behav Brain Res 2011;217:463-466.

30. Kamphuis J, Meerlo P, Koolhaas JM, Lancel M. Poor sleep as a potential causal factor in aggression and violence. Sleep Med 2012;13:327-334.

31. Gruber R, Cassoff J, Frenette S, Wiebe S, Carrier J. Impact of sleep extension and restriction on children's emotional lability and impulsivity. Pediatrics 2012;130:e1155-e1161.

32. Baum KT, Desai A, Field J, Miller LE, Rausch J, Beebe
DW. Sleep restriction worsens mood and emotion regulation in adolescents. $J$ Child Psychol Psychiatry 2014;55: 180-190.

33. Barclay NL, Ellis JG. Genetic influences contribute to neurobehavioral response to acute sleep deprivation. Sleep 2012;35:1191-1192.

34. Basner M, Rao H, Goel N, Dinges DF. Sleep deprivation and neurobehavioral dynamics. Curr Opin Neurobiol 2013;23:854-863.

35. Rosenzweig I, Williams SC, Morrell MJ. The impact of sleep and hypoxia on the brain: potential mechanisms for the effects of obstructive sleep apnea. Curr Opin Pulm Med 2014;20:565-571.

36. Unnikrishnan D, Jun J, Polotsky V. Inflammation in sleep apnea: an update. Rev Endocr Metab Disord 2015;16:25-34.

37. Loffredo L, Zicari AM, Occasi F, Perri L, Carnevale R, Angelico F, et al. Endothelial dysfunction and oxidative stress in children with sleep disordered breathing: role of NADPH oxidase. Atherosclerosis 2015;240:222-227.

38. Lim DC, Pack AI. Obstructive sleep apnea and cognitive impairment: addressing the blood-brain barrier. Sleep Med Rev 2014;18:35-48.

39. Shpirer I, Elizur A, Shorer R, Peretz RB, Rabey JM, Khaigrekht M. Hypoxemia correlates with attentional dysfunction in patients with obstructive sleep apnea. Sleep Breath 2012;16:821-827.

40. Bucks RS, Olaithe M, Eastwood P. Neurocognitive function in obstructive sleep apnoea: a meta-review. Respirology 2013;18:61-70.

41. Vaessen TJ, Overeem S, Sitskoorn MM. Cognitive complaints in obstructive sleep apnea. Sleep Med Rev 2015;19: $51-58$.

42. Grigg-Damberger M, Ralls F. Cognitive dysfunction and obstructive sleep apnea: from cradle to tomb. Curr Opin Pulm Med 2012;18:580-587.

43. Chervin RD, Archbold KH, Dillon JE, Panahi P, Pituch KJ, Dahl RE, et al. Inattention, hyperactivity, and symptoms of sleep-disordered breathing. Pediatrics 2002;109:449-456.

44. Chervin RD, Dillon JE, Bassetti C, Ganoczy DA, Pituch KJ. Symptoms of sleep disorders, inattention, and hyperactivity in children. Sleep 1997;20:1185-1192.

45. Sedky K, Bennett DS, Carvalho KS. Attention deficit hyperactivity disorder and sleep disordered breathing in pediatric populations: a meta-analysis. Sleep Med Rev 2014;18:349-356.

46. Vaher H, Vaikjärv R, Veldi M, Kasenõmm P, Vasar V. Measuring attention deficit with dass test in children with obstructive sleep apnea. Sleep Med 2013;14(Suppl 1):e289.

47. Barnes ME, Gozal D, Molfese DL. Attention in children with obstructive sleep apnoea: an event-related potentials study. Sleep Med 2012;13:368-377.

48. Henriques Filho P, Pratesi R, Gandolfi L, Nobrega Y, Tristao R. Obstructive sleep apnea and P300 abnormalities in children with attention deficit. Sleep Med 2013;14(Suppl 1):e125.

49. Prilipko O, Huynh N, Thomason ME, Kushida CA, Guilleminault C. An fMRI study of cerebrovascular reactivity and perfusion in obstructive sleep apnea patients before and after CPAP treatment. Sleep Med 2014;15:892-898.

50. Weng HH, Tsai YH, Chen CF, Lin YC, Yang CT, Tsai $\mathrm{YH}$, et al. Mapping gray matter reductions in obstructive sleep apnea: an activation likelihood estimation metaanalysis. Sleep 2014;37:167-175.

51. Peng DC, Dai XJ, Gong HH, Li HJ, Nie X, Zhang W. 
Altered intrinsic regional brain activity in male patients with severe obstructive sleep apnea: a resting-state functional magnetic resonance imaging study. Neuropsychiatr Dis Treat 2014;10:1819-1826.

52. Gozal D, Khalyfa A, Capdevila OS, Kheirandish-Gozal L, Khalyfa AA, Kim J. Cognitive function in prepubertal children with obstructive sleep apnea: a modifying role for NADPH oxidase p22 subunit gene polymorphisms? Antioxid Redox Signal 2012;16:171-177.

53. Khalyfa A, Serpero LD, Kheirandish-Gozal L, Capdevila $\mathrm{OS}$, Gozal D. TNF- $\alpha$ gene polymorphisms and excessive daytime sleepiness in pediatric obstructive sleep apnea. $J$ Pediatr 2011;158:77-82.

54. Kaditis AG, Gozal D, Khalyfa A, Kheirandish-Gozal L, Capdevila OS, Gourgoulianis $\mathrm{K}$, et al. Variants in $C$-reactive protein and $I L-6$ genes and susceptibility to obstructive sleep apnea in children: a candidate-gene association study in European American and Southeast European populations. Sleep Med 2014;15:228-235.

55. Wright KP, Lowry CA, Lebourgeois MK. Circadian and wakefulness-sleep modulation of cognition in humans. Front Mol Neurosci 2012;5:50.

56. Jagannath A, Peirson SN, Foster RG. Sleep and circadian rhythm disruption in neuropsychiatric illness. Curr Opin Neurobiol 2013;23:888-894.

57. Carrier J, Monk TH. Circadian rhythms of performance: new trends. Chronobiol Int 2000;17:719-732.

58. Kyriacou CP, Hastings MH. Circadian clocks: genes, sleep, and cognition. Trends Cogn Sci 2010;14:259-267.

59. May CP. Synchrony effects in cognition: the costs and $a$ benefit. Psychon Bull Rev 1999;6:142-147.

60. May CP, Hasher L. Synchrony effects in inhibitory control over thought and action. J Exp Psychol Hum Percept Perform 1998;24:363-379.

61. Schmidt C, Collette F, Leclercq Y, Sterpenich V, Vandewalle G, Berthomier P, et al. Homeostatic sleep pressure and responses to sustained attention in the suprachiasmatic area. Science 2009;324:516-519.

62. Kohyama J. The possible long-term effects of early-life circadian rhythm disturbance on social behavior. Expert Rev Neurother 2014;14:745-755.

63. Wada K, Nakamura K, Tamai Y, Tsuji M, Watanabe K, Ando $\mathrm{K}$, et al. Associations of endogenous melatonin and sleeprelated factors with behavioral problems in preschool Japanese children. Ann Epidemiol 2013;23:469-474.

64. Lange L, Randler C. Morningness eveningness and behavioural problems in adolescents. Sleep Biol Rhythm 2011; 9:12-18

65. Caci H, Bouchez J, Baylé FJ. Inattentive symptoms of ADHD are related to evening orientation. J Atten Disord 2009;13:36-41.

66. Nováková M, Paclt I, Ptáček R, Kuželová H, Hájek I, Sumová A. Salivary melatonin rhythm as a marker of the circadian system in healthy children and those with attention-deficit/hyperactivity disorder. Chronobiol Int 2011;28:630-637.

67. Castellano IP, Cuesta FP, Pitarch AP. Salivary determination of dim light melatonin onset as a tool in attention deficit hyperactivity disorder diagnosis. Sleep Med 2013;14(Suppl 1):e93.

68. Wulff K, Porcheret K, Cussans E, Foster RG. Sleep and circadian rhythm disturbances: multiple genes and multiple phenotypes. Curr Opin Genet Dev 2009;19:237-246.

69. Hida A, Kitamura S, Katayose Y, Kato M, Ono H, Kadotani H, et al. Screening of clock gene polymorphisms demonstrates association of a PER3 polymorphism with morningness-eveningness preference and circadian rhythm sleep disorder. Sci Rep 2014;4:6309.

70. Wulff K, Gatti S, Wettstein JG, Foster RG. Sleep and circadian rhythm disruption in psychiatric and neurodegenerative disease. Nat Rev Neurosci 2010;11:589-599.

71. Cappuccio FP, Taggart FM, Kandala NB, Currie A, Peile $\mathrm{E}$, Stranges S, et al. Meta-analysis of short sleep duration and obesity in children and adults. Sleep 2008;31:619-626.

72. Chen X, Beydoun MA, Wang Y. Is sleep duration associated with childhood obesity? A systematic review and meta-analysis. Obesity (Silver Spring) 2008;16:265-274.

73. Hasler G, Buysse DJ, Klaghofer R, Gamma A, Ajdacic V, Eich $\mathrm{D}$, et al. The association between short sleep duration and obesity in young adults: a 13-year prospective study. Sleep 2004;27:661-666.

74. Marshall NS, Glozier N, Grunstein RR. Is sleep duration related to obesity? A critical review of the epidemiological evidence. Sleep Med Rev 2008;12:289-298.

75. von Kries R, Toschke AM, Wurmser H, Sauerwald T, Koletzko B. Reduced risk for overweight and obesity in 5and 6-y-old children by duration of sleep--a cross-sectional study. Int J Obes Relat Metab Disord 2002;26:710-716.

76. Spiegel K, Tasali E, Leproult R, Van Cauter E. Effects of poor and short sleep on glucose metabolism and obesity risk. Nat Rev Endocrinol 2009;5:253-261.

77. Spiegel K, Knutson K, Leproult R, Tasali E, Van Cauter E. Sleep loss: a novel risk factor for insulin resistance and Type 2 diabetes. J Appl Physiol (1985) 2005;99:20082019.

78. Nieto FJ, Young TB, Lind BK, Shahar E, Samet JM, Redline S, et al. Association of sleep-disordered breathing, sleep apnea, and hypertension in a large community-based study. Sleep Heart Health Study. JAMA 2000;283:18291836.

79. Ip MS, Lam B, Ng MM, Lam WK, Tsang KW, Lam KS. Obstructive sleep apnea is independently associated with insulin resistance. Am J Respir Crit Care Med 2002;165: 670-676.

80. Gangwisch JE, Malaspina D, Babiss LA, Opler MG, Posner K, Shen S, et al. Short sleep duration as a risk factor for hypercholesterolemia: analyses of the National Longitudinal Study of Adolescent Health. Sleep 2010;33: 956-961.

81. Taheri S, Lin L, Austin D, Young T, Mignot E. Short sleep duration is associated with reduced leptin, elevated ghrelin, and increased body mass index. PLoS Med 2004;1:e62.

82. Omisade A, Buxton OM, Rusak B. Impact of acute sleep restriction on cortisol and leptin levels in young women. Physiol Behav 2010;99:651-656.

83. Leproult R, Copinschi G, Buxton O, Van Cauter E. Sleep loss results in an elevation of cortisol levels the next evening. Sleep 1997;20:865-870.

84. Dzaja A, Dalal MA, Himmerich H, Uhr M, Pollmächer T, Schuld A. Sleep enhances nocturnal plasma ghrelin levels in healthy subjects. Am J Physiol Endocrinol Metab 2004;286:E963-E967.

85. McEwen BS. Sleep deprivation as a neurobiologic and physiologic stressor: Allostasis and allostatic load. Metabolism 2006;55(10 Suppl 2):S20-S23.

86. Knutson KL, Spiegel K, Penev P, Van Cauter E. The metabolic consequences of sleep deprivation. Sleep Med Rev 2007;11:163-178.

87. Verhulst SL, Schrauwen N, Haentjens D, Rooman RP, Van Gaal L, De Backer WA, et al. Sleep-disordered breathing 
and the metabolic syndrome in overweight and obese children and adolescents. J Pediatr 2007;150:608-612.

88. Moreno-Indias I, Torres M, Montserrat JM, SanchezAlcoholado L, Cardona F, Tinahones FJ, et al. Intermittent hypoxia alters gut microbiota diversity in a mouse model of sleep apnoea. Eur Respir J 2015;45:1055-1065.

89. Li J, Thorne LN, Punjabi NM, Sun CK, Schwartz AR, Smith $\mathrm{PL}$, et al. Intermittent hypoxia induces hyperlipidemia in lean mice. Circ Res 2005;97:698-706.

90. Li J, Grigoryev DN, Ye SQ, Thorne L, Schwartz AR, Smith PL, et al. Chronic intermittent hypoxia upregulates genes of lipid biosynthesis in obese mice. J Appl Physiol (1985) 2005;99:1643-1648.

91. Drager LF, Jun JC, Polotsky VY. Metabolic consequences of intermittent hypoxia: relevance to obstructive sleep apnea. Best Pract Res Clin Endocrinol Metab 2010;24:843-851.

92. Kim TW, Jeong JH, Hong SC. The impact of sleep and circadian disturbance on hormones and metabolism. Int $J$ Endocrinol 2015;2015:591729.

93. Bray MS, Young ME. Circadian rhythms in the development of obesity: potential role for the circadian clock within the adipocyte. Obes Rev 2007;8:169-181.

94. Vieira E, Burris TP, Quesada I. Clock genes, pancreatic function, and diabetes. Trends Mol Med 2014;20:685-693.

95. Dewald JF, Meijer AM, Oort FJ, Kerkhof GA, Bögels SM. The influence of sleep quality, sleep duration and sleepiness on school performance in children and adolescents: a meta-analytic review. Sleep Med Rev 2010;14:179-189.

96. Titova OE, Hogenkamp PS, Jacobsson JA, Feldman I, Schiöth HB, Benedict C. Associations of self-reported sleep disturbance and duration with academic failure in community-dwelling Swedish adolescents: sleep and academic performance at school. Sleep Med 2015;16:87-93.

97. Asarnow LD, McGlinchey E, Harvey AG. The effects of bedtime and sleep duration on academic and emotional outcomes in a nationally representative sample of adolescents. J Adolesc Health 2014;54:350-356.

98. Stea TH, Knutsen T, Torstveit MK. Association between short time in bed, health-risk behaviors and poor academic achievement among Norwegian adolescents. Sleep Med 2014;15:666-671.

99. Seo D, So WY. Sleep duration and school performance in Korean adolescents. Salud Ment 2014;37:407-413.

100. Li S, Arguelles L, Jiang F, Chen W, Jin X, Yan C, et al. Sleep, school performance, and a school-based intervention among school-aged children: a sleep series study in China. PLoS One 2013;8:e67928.

101. Kronholm E, Puusniekka R, Jokela J, Villberg J, Urrila AS, Paunio $\mathrm{T}$, et al. Trends in self-reported sleep problems, tiredness and related school performance among Finnish adolescents from 1984 to 2011. J Sleep Res 2015;24:3-10.

102. Curcio G, Ferrara M, De Gennaro L. Sleep loss, learning capacity and academic performance. Sleep Med Rev 2006; 10:323-337.

103. Gottlieb DJ, Vezina RM, Chase C, Lesko SM, Heeren TC, Weese-Mayer DE, et al. Symptoms of sleep-disordered breathing in 5-year-old children are associated with sleepiness and problem behaviors. Pediatrics 2003;112:870-877.

104. Gozal D. Sleep-disordered breathing and school performance in children. Pediatrics 1998;102:616-620.

105. Gozal D, Pope DW Jr. Snoring during early childhood and academic performance at ages thirteen to fourteen years. Pediatrics 2001;107:1394-1399.

106. Perez-Chada D, Perez-Lloret S, Videla AJ, Cardinali D, Bergna MA, Fernández-Acquier M, et al. Sleep disordered breathing and daytime sleepiness are associated with poor academic performance in teenagers. A study using the Pediatric Daytime Sleepiness Scale (PDSS). Sleep 2007;30: 1698-1703.

107. Biggs SN, Vlahandonis A, Anderson V, Bourke R, Nixon GM, Davey MJ, et al. Long-term changes in neurocognition and behavior following treatment of sleep disordered breathing in school-aged children. Sleep 2014;37:77-84.

108. Bourke R, Anderson V, Yang JS, Jackman AR, Killedar A, Nixon GM, et al. Cognitive and academic functions are impaired in children with all severities of sleep-disordered breathing. Sleep Med 2011;12:489-496.

109. Chervin RD, Clarke DF, Huffman JL, Szymanski E, Ruzicka DL, Miller V, et al. School performance, race, and other correlates of sleep-disordered breathing in children. Sleep Med 2003;4:21-27.

110. Preckel F, Lipnevich AA, Schneider S, Roberts RD. Chronotype, cognitive abilities, and academic achievement: A meta-analytic investigation. Learn Individ Differ 2011;21:483-492.

111. Vollmer C, Pötsch F, Randler C. Morningness is associated with better gradings and higher attention in class. Learn Individ Differ 2013;27:167-173.

112. Natale V, Alzani A, Cicogna P. Cognitive efficiency and circadian typologies: a diurnal study. Personal Individ Differ 2003;35:1089-1105.

113. Seifer R, Sameroff AJ, Dickstein S, Hayden LC. Parental psychopathology and sleep variation in children. Child Adolesc Psychiatr Clin N Am 1996;5:715-727.

114. Gelman VS, King NJ. Wellbeing of mothers with children exhibiting sleep disturbance. Aust J Psychol 2001;53: $18-22$.

115. Meltzer LJ, Mindell JA. Relationship between child sleep disturbances and maternal sleep, mood, and parenting stress: a pilot study. J Fam Psychol 2007;21:67-73.

116. Morrell J, Steele H. The role of attachment security, temperament, maternal perception, and caregiving behavior in persistent infant sleeping problems. Infant Ment Health J 2003;24:447-468.

117. Sadeh A, Lavie P, Scher A. Sleep and temperament: Maternal perceptions of temperament of sleep-disturbed toddlers. Early Educ Develop 1994;5:311-322.

118. Owens-Stively J, Frank N, Smith A, Hagino O, Spirito A, Arrigan $\mathrm{M}$, et al. Child temperament, parenting discipline style, and daytime behavior in childhood sleep disorders. J Dev Behav Pediatr 1997;18:314-321.

119. Dahl RE, El-Sheikh M. Considering sleep in a family context: introduction to the special issue. J Fam Psychol 2007;21:1-3.

120. Cipolla-Neto J, Amaral FG, Afeche SC, Tan DX, Reiter RJ. Melatonin, energy metabolism, and obesity: a review. J Pineal Res 2014;56:371-381.

121. García JJ, López-Pingarrón L, Almeida-Souza P, Tres A, Escudero P, García-Gil FA, et al. Protective effects of melatonin in reducing oxidative stress and in preserving the fluidity of biological membranes: a review. J Pineal Res 2014; 56:225-237.

122. Favero G, Rodella LF, Reiter RJ, Rezzani R. Melatonin and its atheroprotective effects: a review. Mol Cell Endocrinol 2014;382:926-937.

123. Zhang L, Zhang HQ, Liang XY, Zhang HF, Zhang T, Liu FE. Melatonin ameliorates cognitive impairment induced by sleep deprivation in rats: role of oxidative stress, BDNF and CaMKII. Behav Brain Res 2013;256:72-81.

124. Zhdanova IV, Wang SY, Leclair OU, Danilova NP. 
Melatonin promotes sleep-like state in zebrafish. Brain Res 2001;903:263-268.

125. Papp M, Litwa E, Gruca P, Mocaër E. Anxiolytic-like activity of agomelatine and melatonin in three animal models of anxiety. Behav Pharmacol 2006;17:9-18.

126. Van der Heijden KB, Smits MG, Van Someren EJ, Ridderinkhof KR, Gunning WB. Effect of melatonin on sleep, behavior, and cognition in ADHD and chronic sleep-onset insomnia. J Am Acad Child Adolesc Psychiatry 2007; 46:233-241.

127. Bendz LM, Scates AC. Melatonin treatment for insomnia in pediatric patients with attention-deficit/hyperactivity disorder. Ann Pharmacother 2010;44:185-191.

128. Hoebert M, van der Heijden KB, van Geijlswijk IM, Smits MG. Long-term follow-up of melatonin treatment in children with ADHD and chronic sleep onset insomnia. J Pineal Res 2009;47:1-7.

129. Schwartz RS, Olds J. The psychiatry of light. Harv Rev Psychiatry 2015;23:188-194.

130. Arns M, van der Heijden KB, Arnold LE, Kenemans JL. Geographic variation in the prevalence of attentiondeficit/hyperactivity disorder: the sunny perspective. Biol Psychiatry 2013;74:585-590.

131. Rybak YE, McNeely HE, Mackenzie BE, Jain UR, Levitan RD. An open trial of light therapy in adult attention-deficit/ hyperactivity disorder. J Clin Psychiatry 2006;67:1527-1535.

132. Niederhofer H. Stabilization of circadian rhythm, its augmentation by bright light treatment and its importance for ADHD and depression of adolescents. Neurosci Med 2013;4:150-154.

133. Huang YS, Guilleminault C, Li HY, Yang CM, Wu YY, Chen NH. Attention-deficit/hyperactivity disorder with obstructive sleep apnea: a treatment outcome study. Sleep Med 2007;8:18-30.

134. Guilleminault C, Huang YS, Monteyrol PJ, Sato R, Quo $\mathrm{S}$, Lin $\mathrm{CH}$. Critical role of myofascial reeducation in pediatric sleep-disordered breathing. Sleep Med 2013;14: 518-525.

135. Moeller JL, Paskay LC, Gelb ML. Myofunctional therapy: a novel treatment of pediatric sleep-disordered breathing. Sleep Med Clin 2014;9:235-243.

136. Villa MP, Brasili L, Ferretti A, Vitelli O, Rabasco J, Mazzotta AR, et al. Oropharyngeal exercises to reduce symptoms of OSA after AT. Sleep Breath 2015;19:281-289.

137. Huang YS, Guilleminault C. Pediatric obstructive sleep apnea and the critical role of oral-facial growth: evidences. Front Neurol 2013;3:184.
138. Lofthouse N, Arnold LE, Hersch S, Hurt E, DeBeus R. $A$ review of neurofeedback treatment for pediatric ADHD. $J$ Atten Disord 2012;16:351-372.

139. Arns M, de Ridder S, Strehl U, Breteler M, Coenen A. Efficacy of neurofeedback treatment in ADHD: the effects on inattention, impulsivity and hyperactivity: a meta-analysis. Clin EEG Neurosci 2009;40:180-189.

140. Cortoos A, De Valck E, Arns M, Breteler MH, Cluydts R. An exploratory study on the effects of tele-neurofeedback and tele-biofeedback on objective and subjective sleep in patients with primary insomnia. Appl Psychophysiol Biofeedback 2010;35:125-134.

141. Hoedlmoser K, Pecherstorfer T, Gruber G, Anderer P, Doppelmayr M, Klimesch $\mathrm{W}$, et al. Instrumental conditioning of human sensorimotor rhythm $(12-15 \mathrm{~Hz})$ and its impact on sleep as well as declarative learning. Sleep 2008;31:1401-1408.

142. Arns M, Kenemans JL. Neurofeedback in ADHD and insomnia: vigilance stabilization through sleep spindles and circadian networks. Neurosci Biobehav Rev 2014;44: 183-194.

143. Boergers J, Gable CJ, Owens JA. Later school start time is associated with improved sleep and daytime functioning in adolescents. J Dev Behav Pediatr 2014;35:11-17.

144. Carrell SE, Maghakian T, West JE. A's from Zzzz's? The causal effect of school start time on the academic achievement of adolescents. Am Econ J Econ Policy 2011;3:62-81.

145. Lufi D, Tzischinsky O, Hadar S. Delaying school starting time by one hour: some effects on attention levels in adolescents. J Clin Sleep Med 2011;7:137-143.

146. Anacleto TS, Adamowicz T, Simões da Costa Pinto L, Louzada FM. School schedules affect sleep timing in children and contribute to partial sleep deprivation. Mind Brain Educ 2014:8:169-174.

147. Silva TA, Carvalho LB, Silva L, Medeiros M, Natale VB, Carvalho JE, et al. Sleep habits and starting time to school in Brazilian children. Arq Neuropsiquiatr 2005;63:402-406.

148. Owens JA, Belon K, Moss P. Impact of delaying school start time on adolescent sleep, mood, and behavior. Arch Pediatr Adolesc Med 2010;164:608-614.

149. Adolescent Sleep Working Group; Committee on Adolescence; Council on School Health. School start times for adolescents. Pediatr 2014;134:642-649.

150. Hirshkowitz M, Whiton K, Albert SM, Alessi C, Bruni O, DonCarlos L, et al. National Sleep Foundation's sleep time duration recommendations: methodology and results summary. Sleep Health 2015;1:40-43. 